\title{
LA CONFIANZA EN LAS ZONAS MINERAS DE ANTIOQUIA, BOLÍVAR Y CÓRDOBA
}

\author{
Santiago Silva, Adolfo Eslava, \\ Andrés Preciado, Oswaldo Zapata, \\ Laura Correa, Jorge Giraldo*
}

\begin{abstract}
Z ste artículo examina las motivaciones y reglas de interacción - social en áreas distantes de las ciudades. Desde una perspectiva que combina aspectos cualitativos, cuantitativos y experimentales, explora la corrupción y sus nexos con la confianza en 17 municipios mineros ${ }^{1}$. Es necesaria entender las reglas que predominan en esos territorios para enfrentar la inercia que condena a sus habitantes a jugar un papel secundario en las soluciones que ofrece el Estado.
\end{abstract}

\section{ECOLOGÍA DE LA CORRUPCIÓN Y ESCENARIOS DE CONFIANZA}

\section{ECOLOGÍA DE LA CORRUPCIÓN}

La corrupción es la violación de un deber asociado a un cargo público o privado, la transgresión de una norma para obtener un beneficio -no necesariamente económico o personal-y el intento de ocultar la

\footnotetext{
* Los autores son, respectivamente, politólogo y docente de la Universidad EAFIT, [ssilvaja@eafit.edu.co]; candidato a doctor en Estudios Políticos y profesor de la Universidad EAFIT, Medellín, Colombia, [aeslava@eafit.edu.co]; politólogo e investigador en la FIP, Bogotá, Colombia, [apreciad@eafit.edu.co]; economista y Director Técnico del SISC, Alcaldía de Medellín, [oswaldo.zapataq@gmail.com]; abogada y docente de la Universidad EAFIT, [1corre22@eafit.edu.co]; doctor en Filosofía, decano y profesor de la Escuela de Ciencias y Humanidades de la Universidad EAFIT, [jorgegiraldo@eafit.edu.co]. Este artículo es parte de un trabajo financiado por Colciencias a cargo del grupo de investigación Sociedad, política e historias conectadas, de la Universidad EAFIT. Fecha de recepción: 8 de julio de 2014, fecha de modificación: 28 de abril de 2015, fecha de aceptación: 29 de octubre de 2015. Sugerencia de citación: Silva, S.; A. Eslava, A. Preciado, O. Zapata, L. Correa y J. Giraldo. "La confianza en las zonas mineras de Antioquia, Bolívar y Córdoba", Revista de Economía Institucional 17, 33, 2015, pp. 231-251. DOI: http://dx.doi.org/10.18601/01245996.v17n33.10

${ }^{1}$ Antioquia: Tarazá, Segovia, Maceo, Remedios, Nechí, El Bagre, Cáceres, Caucasia, Cañasgordas y Zaragoza. Bolívar: Simití, Montecristo, San Pablo y Santa Rosa del Sur. Córdoba: Buena Vista, Puerto Libertador y Ayapel. Los demás resultados se presentan en Eslava (2014).
} 
acción (Misas et al., 2005, 30). También se puede entender como un comportamiento ilegal o pseudolegal de la élite política para poner los asuntos del Estado a su servicio (Uslaner, 2004). La corrupción destroza la justicia y da ventajas a unas personas sobre otras. Puede afectar todos los ámbitos de la experiencia de las personas y las organizaciones. Además, destruye la fibra moral, deteriora el respeto por la ley y la fe entre sus miembros, y puede llevar a bajos niveles de crecimiento económico y a gobiernos ineficientes (ibíd.).

Aunque es un problema universal, muchas sociedades han logrado contener sus efectos más perjudiciales por medio de políticas públicas y esfuerzos bien encaminados y sostenidos. Es necesario tener en cuenta esos logros porque "el mundo moderno ha llegado a darse cuenta de que los valores éticos, la integridad y el buen gobierno son los cimientos de un Estado exitoso" (de Speville, 2011, 29).

Se pueden identificar dos niveles de corrupción. El de bajo nivel (Rose, 2010, 136), que involucra individuos y funcionarios de baja posición en una organización pero con alguna discreción para tomar decisiones; el intercambio no requiere gran acceso a información ni un esfuerzo coordinado con otros actores. Y el de gran escala (ibíd., 138139), en el que la posición de los involucrados es más alta y mayor su discreción y poder para decidir, y se debe coordinar la acción de varias o muchas personas; este puede ser de tres tipos: monopolización de sobornos, corrupción del sistema electoral y trasferencia de recursos del Estado por medio de la inversión y el gasto público.

El intercambio asociado a la corrupción se puede estudiar empleando el concepto de mercancía política, el "conjunto de bienes o servicios compuestos por recursos políticos [...] que pueden [ser] objeto privado de apropiación para el intercambio [...] por otras mercancías, utilidades o dinero", el cual puede ser libre o forzado, legal o ilegal, criminal o no. Este concepto es útil para analizar las negociaciones asociadas a la corrupción, el clientelismo, la extorsión, el tráfico de influencias y el fraude, que son procesos sociales y no solo económicos, del "mercado ilegal".

Misse no se centra en la corrupción como excepción a las reglas. Va más allá de estudiar las prácticas corruptas aisladas que afectan a toda sociedad introduciendo el concepto de "mercancía política" en un mercado que la comercializa y en un contexto donde "las normas morales universalmente aceptadas en el Estado moderno se pueden relajar y reinterpretar contextualmente" (Misse, 2013, 14). Hay una distancia entre la concepción típico-ideal de una norma y su aplicación, a la que Misse llama “desviación”. En la valoración moral de las transgresiones legales en situaciones concretas existe una gradación, 
que en muchos casos no corresponde a la sanción legal. En un soborno, por ejemplo, "los ciudadanos y agentes estatales interpretan la validez o no del evento para cada caso contemplado en los códigos, y también realizan una adecuación de sentido entre la norma moral y el (presunto) sentido de la ley para realizarla" (ibíd., 18). Misse llama "neutralización de la culpa" a este proceso, en el que intervienen argumentos populares que universalizan ("todos lo hacen”) o particularizan ("es un caso especial") ese comportamiento.

Para explicar la diferencia entre acciones toleradas y no toleradas, Misse emplea el término "criminación”, que distingue la criminalización (por la cual una ley moral forma parte del entramado penal) y la forma en que los individuos interpretan los hechos en situaciones específicas. De modo que no todos los actos criminalizados por el Estado son "criminados" por los individuos involucrados en una transgresión concreta. En esencia, este autor brasileño diferencia la criminalización conceptual (legal) de la incriminación real: "la distinción entre moral pública y moral privada no siempre es clara para los actores y varía de acuerdo con los intereses en juego, basados en el ethos democrático moderno en un extremo y el ethos egoísta individualista en el otro" (ibíd., 22). Este fenómeno se relaciona estrechamente con lo que Banfield (1958) llamó "familismo amoral".

Las transacciones asociadas a las mercancías políticas "hieren más la moral pública que la privada, alcanzan más al Estado que al individuo, las empresas o las familias, y aspiran a una legitimidad particularista o, por lo menos en algunos casos, buscan alguna justificación contextual" (Misse, 22). Para Misse su gravedad se refleja en cinco elementos: la criminalización, la reacción moral efectiva, la eficiencia de la neutralización, el monopolio de la mercancía y el carácter más o menos obligatorio de la transacción (ibíd., 24) ${ }^{2}$. Todos ellos influyen en el intercambio de mercancías políticas y el cálculo de los costos políticos y económicos que hacen los involucrados.

Las ideas de mercancía política y criminación o tolerancia ayudan a entender la corrupción como un fenómeno que responde a una ecología de factores de riesgo. Es decir, las prácticas corruptas son incentivadas por ciertas condiciones ambientales. Ninguno de los elementos mencionados es suficiente para explicarlas, pero pueden pertenecer a un "caldo de cultivo" con altos incentivos para que ocurran. Su mayor presencia en un ámbito específico implica un mayor

2 La gravedad indica el grado en que una sociedad considera socialmente perjudicial o inconveniente una transgresión particular. En este caso, el término "mercancía política" se refiere a transacciones como el intercambio de favores entre un cliente y su patrón o un soborno para ganar una licitación. 
riesgo para que haya casos de corrupción. Ver la corrupción desde un punto de vista ecológico implica, además, que los cambios en el entorno se reflejan necesariamente en un cambio en la experiencia de los actores, en sus elecciones e interacciones y en su comportamiento.

Hay factores que incentivan las prácticas corruptas y que configuran esta "ecología" de la corrupción (Orrego, 2000). En el ámbito socio-político: el clientelismo, el costo creciente de la vida política, la baja aceptación de la ley y la autoridad, la falta de transparencia y de alternación política, la descentralización acelerada y, en general, las debilidades del sistema democrático. En el ámbito de las organizaciones: las asimetrías de poder, la debilidad técnica, el excesivo legalismo o la excesiva discrecionalidad de los funcionarios. En el ámbito jurídico ciertos arreglos pueden incentivarlas en vez de disminuirlas: un énfasis excesivo en el derecho penal y una legislación incompleta, inestable u obsoleta. Por último, factores ético-culturales, que denotan la incidencia de los valores en la disposición a participar o no en prácticas corruptas (Orrego, 2000, 26), como el predominio de la avaricia, el rechazo a los cursos de acción convencionales y la justificación de cursos alternos para conseguir beneficios personales, el nepotismo, el clientelismo y el tráfico de influencias.

"Cuando las élites explotan el Estado en su propio beneficio, el público llega a aceptar el robo como parte de su vida diaria" (Uslaner, 2004, 6). La corrupción no es entonces un comportamiento selectivo y particular cuyos culpables se diferencian e identifican con facilidad, sino que se integra en la cultura política. La corrupción aparece cuando hay bajos niveles de confianza general y altos niveles de confianza entre miembros de grupos pequeños.

\section{ESCENARIOS DE CONFIANZA}

E1 capital social promueve la cooperación basada en la confianza y la disposición a la acción colectiva. Aunque no todas las normas son fuentes de capital social, deben promover la cooperación entre individuos o grupos y estar asociadas a valores y virtudes como "la honestidad, la honra de compromisos, el cumplimiento del deber y la reciprocidad" (Fukuyama, 2000,3). Un grupo puede mejorar su capital social si extiende la confianza entre personas ajenas. La distribución social del capital social se puede representar mediante "radios de confianza" (ibíd.), los círculos de personas que funcionan con normas cooperativas y pueden ser mayores o menores que el grupo específico. Las sociedades modernas pueden verse como una serie de radios de confianza concéntricos y sobrepuestos. La solidaridad excesiva dentro 
de un grupo lleva a desconfiar del exterior y genera externalidades sociales negativas.

Sin un buen nivel de capital social, la coordinación es posible pero muy costosa, pues este "aceita" las relaciones entre individuos y grupos, y reduce los costos de supervisión en escenarios de prevención y desconfianza; incluso en la sociedad moderna, donde es esencial para la acción de la sociedad civil que balancea el poder del Estado y promueve el interés colectivo. En sociedades con bajo nivel o una distribución asimétrica del capital social suelen existir un sistema administrativo rígido e irresponsable, ineficiencia y corrupción estatal, y códigos morales diferentes en los grupos y en la sociedad.

Gambetta identifica dos procesos de destrucción del capital social. Uno relacionado con la desconfianza en el sistema legal y de justicia, donde el primer paso "es eminentemente político y tiene que ver con la falta de sistemas fiables y eficaces de justicia y aplicación de la ley" $(2000,160)$, y el segundo el escepticismo hacia el Estado, que se transforma en fuente de desconfianza hacia las demás personas. La falta de credibilidad en el Estado alienta "otro proceso [...] la desconfianza se filtra en la escala social, y la imprevisibilidad de las sanciones provoca incertidumbre sobre los acuerdos, estancamiento del comercio y la industria, y una renuencia general a las formas impersonales de cooperación" (ibíd., 161). Hay una imbricación entre confianza interpersonal y confianza en las instancias políticas. Las personas tienden a obedecer la ley cuando hacen parte de un sistema legal que las trata con justicia, no por miedo al castigo; de modo que la confianza en el Estado las induce a cumplir las normas que promueven y a establecer relaciones interpersonales de confianza.

Los ciudadanos cumplen las exigencias del Estado cuando perciben que el gobierno es digno de confianza y que hay reciprocidad en el resto de la sociedad. Tilly subrayó que "la justicia y la equidad importan" (2005, 42), y Uslaner añadió: "cuando las personas han perdido la fe en los demás y creen que sus líderes son corruptos y la desigualdad es rampante, tendrán poca fe en que otra burocracia pueda combatir la corrupción" $(2009,15)$; y mostró que las personas tienden a respetar los códigos morales y legales -sin importar lo duros que sean- en su círculo de confianza.

Partiendo de la definición de capital social como la confianza en la buena fe de los demás, Morck y Yeung (2004) muestran que el familismo amoral lleva a confiar en los parientes o amigos cercanos y a desconfiar de los demás y "deja a las familias como la única estructura económica viable” (ibíd., 395). Esto sucede allí donde el interés 
individual y familiar supera el interés público revestido de nepotismo y egoísmo. Los problemas de desarrollo económico y político de esas sociedades se pueden explicar en parte por la incapacidad para actuar conjuntamente por el bien común o por algún fin que vaya más allá del beneficio material de la familia (Banfield, 1958), como en las condiciones de explotación de oro que tratamos más adelante.

La corrupción puede ser sistemática, y como acción organizada requiere la confianza particular y estratégica entre los participantes. Los corruptos dependen de personas como ellos y confían en extraños en situaciones riesgosas; y solo pueden asumir los riesgos si aseguran que sus socios cumplan sus promesas. Por ello es difícil entrar en una red de corrupción. La selección de quienes entran o no en el "radio de confianza" no se deja a la confianza general. Solo la confianza particular y estratégica garantiza el funcionamiento de esas redes (Uslaner, 2009). El problema no es entonces el bajo nivel de confianza general, sino su distribución desigual entre los radios. Un gran volumen de capital social puede ser perjudicial si está mal distribuido. La desigualdad entre radios de confianza puede llevar a la creación de grupos que solo buscan su interés privado. Entre las élites empresariales y gubernamentales hay suficiente confianza particular y estratégica para involucrarse en actividades corruptas; el resto de la sociedad carece de lazos de confianza para combatir los sobornos y la venta de favores de la élite.

En sociedades con alta concentración del ingreso suele haber poca confianza general. La desconfianza se extiende allí donde las personas se preguntan por qué unos pocos consiguieron tanto y ellas muy poco. La desigualdad económica destruye el capital social, y donde es rampante es un reflejo de injusticia y arbitrariedad que cuestiona las reglas sociales; la gente "siente que hay juego sucio, que eso no debería suceder” (Kliksberg, 2007, 272). Esa sensación lleva a usar "métodos alternativos" para lograr los fines individuales. El rechazo de la corrupción es bajo cuando se desconfía de los demás y se cree que están prestos a engañar.

La desigualdad en las decisiones públicas y el acceso concentrado a los recursos del Estado suscitan desconfianza y corrupción porque permiten aprovechar las instancias políticas y legales en beneficio de intereses particulares. Los agentes corruptos no solo usan su ascendencia en la arena pública para conseguir prerrogativas personales; las redes clientelistas se construyen a partir de la desigualdad económica y política. 


\section{ORO Y CONFIANZA: ARREGLOS MICROINSTITUCIONALES EN LAS ZONAS MINERAS}

La investigación de la que forma parte este artículo intenta esclarecer los arreglos microinstitucionales en las zonas mineras de Antioquia, Bolívar y Córdoba ${ }^{3}$. Los resultados del trabajo de campo sugieren que algunos aspectos clave (reglas formales e informales y atributos de la comunidad $)^{4}$ de esos arreglos incentivan las prácticas corruptas. En 5 de los 17 municipios -Cañargordas, Segovia y Tarazá; San Pablo, y Puerto Libertador- se hicieron tres experimentos: los juegos de la confianza, la acción colectiva y la disposición a la trampa. Además, se hicieron entrevistas semi-estructuradas a profundidad, y algunas de carácter informal. Los criterios para seleccionarlos fueron la producción de oro entre 2001 y 2012, el desempeño medido por el Índice de Gobierno Abierto 2011, el puntaje del Índice de Riesgo de Victimización 2012, para que reflejaran escenarios y combinaciones diferentes de esos criterios y representaran a los tres departamentos.

\section{Gráfica 1}

Producción total de oro en los 17 municipios de la muestra (Toneladas)

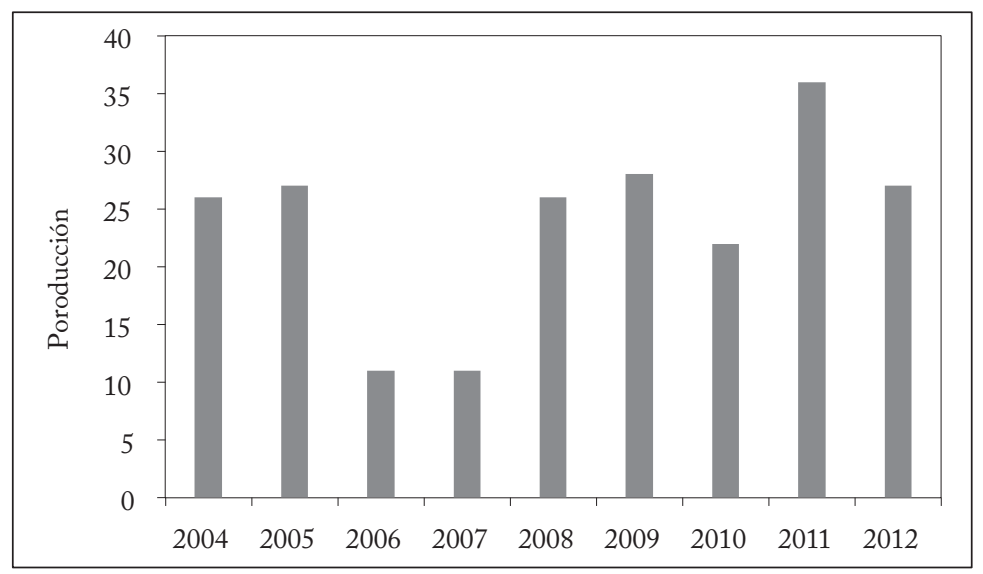

Fuente: SIMCO, 2013, elaboración propia.

\footnotetext{
3 Los factores institucionales y culturales afectan el comportamiento y las expectativas de las personas (Ostrom, 2009). El arreglo microinstitucional denota las reglas que predominan en la interacción cotidiana; en los territorios mineros hay un apego arbitrario a tales reglas.

${ }^{4}$ Las reglas son los preceptos, regulaciones e instrucciones; los atributos incluyen el nivel de comprensión, la homogeneidad de las preferencias, el tamaño, la composición y la distribución de bienes básicos (Ostrom y Polski, 1999).
} 
De larga tradición minera y con una larga historia de conflicto social y armado, esta región es una de las que más regalías directas recibe por la explotación de oro, cuyos altos precios en los últimos años (al menos hasta 2012, el año de corte) han inducido una mayor extracción (gráfica 1). Ese auge reciente ocurrió en una región de larga tradición en la minería aurífera, golpeada por el conflicto armado y con graves problemas de ausencia, falta de credibilidad y debilidad del Estado, cuya incapacidad para vigilar y controlar la actividad económica es una de las principales causas de la aparición de actividades informales con costos relativamente bajos. En el nacimiento de estas economías informales intervienen otros elementos: el alto costo de la formalización, la desconfianza en el Estado, la dinámica del conflicto armado, un mercado excluyente, las prohibiciones y regulaciones restrictivas, y la sobrepoblación.

Por su parte, la minería informal de oro está signada por la incertidumbre y la inestabilidad. La movilidad natural de la actividad, que implica un movimiento continuo, y la falta de técnica y recursos para la exploración a pequeña escala provocan gran incertidumbre. La minería de aluvión es de corto plazo, suele ser empírica y poco tecnificada, y genera altos y rápidos beneficios con baja inversión inicial (dada la evasión de las normas ambientales, del pago de la renta minera, de impuestos, seguridad social e industrial), lo que quizá explique la inclinación a gastar esos beneficios rápidamente y en bienes y servicios conspicuos. La acumulación, el ahorro y la inversión son poco comunes. Como dijo un congresista entrevistado: "entre muchos de los pequeños mineros existe muy poca preocupación por el futuro", y confirma un minero: "los mineros no piensan en el largo plazo, solo en el día [...] no tienen cultura del ahorro, de progreso, no tienen visión de futuro sino de inmediatez, por eso lo dejan todo en los bares, el juego y las mujeres" (minero entrevistado en Segovia).

La población ligada a la minería informal es flotante, y esto genera grandes dificultades para que haya arraigo y compromiso con el municipio en el que se extrae oro ${ }^{5}$. Esos movimientos de población son una fuente de desconfianza general; la población de las zonas mineras recibe con recelo a los mineros recién llegados. La inestabilidad de la explotación debilita las perspectivas de futuro y la confianza entre

\footnotetext{
${ }^{5}$ La movilidad permanente también afecta la confianza dentro de las organizaciones de pequeños mineros. Con respecto a los recién llegados, un líder del Sur de Bolívar comentó: "le damos prioridad a la gente que es de la región porque sabemos que tiene su finca, que tiene sus necesidades y que tiene su forma de subsistir, entonces les decimos listo, con usted no hay ningún problema, entonces hágale, vaya trabaje y sabemos que va a invertir".
} 
los mineros, mientras que los grandes beneficios con poca inversión incentivan el gasto suntuoso en desmedro de la inversión. Y el abandono estatal y la informalidad despiertan un escepticismo natural hacia la regulación e intervención del Estado en la explotación minera.

Gráfica 2

Resultados del juego de confianza

(Porcentaje)

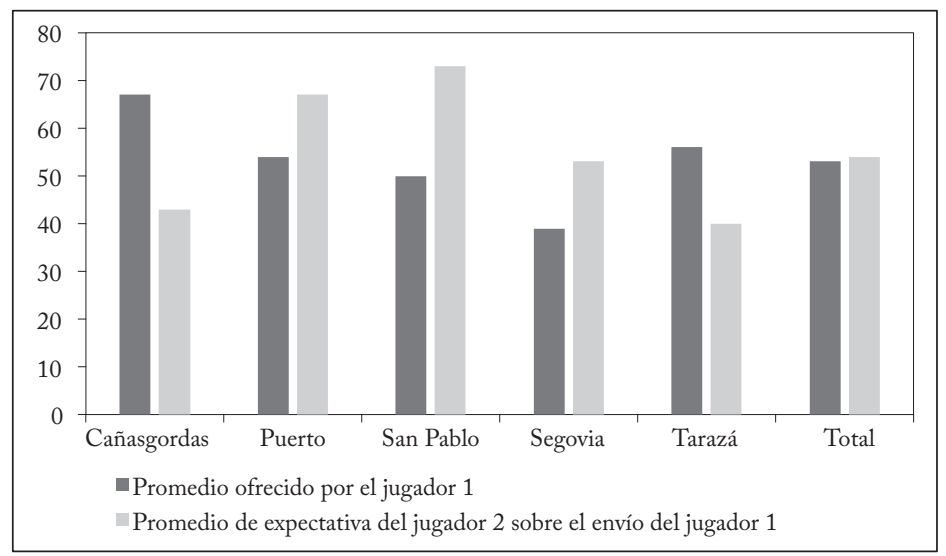

Fuente: elaboración propia.

Los resultados de las encuestas realizadas luego de hacer los experimentos muestran que solo el $13,2 \%$ cree que se puede confiar en las personas y el $86,8 \%$ dice que es necesario ser cuidadoso al tratar con la gente. Las mujeres, las personas mayores y las más educadas son más confiadas. Los mineros que participaron en los experimentos fueron menos confiados: el 6\% apoyó el primer enunciado, mientras que los miembros de organizaciones sociales fueron más confiados, el $32,3 \%$. La gráfica 2 muestra los resultados del juego de la confianza (envío del jugador 1) y la reciprocidad (expectativa del jugador 2).

El análisis de la información acopiada en los experimentos da luces sobre los vínculos entre algunos aspectos de la percepción de confianza y de corrupción. Aquí se presentan cinco correlaciones entre siete variables: percepción de la confianza en la comunidad, percepción de la confianza en el sistema judicial, percepción de la confianza en la alcaldía del municipio de residencia, porcentaje de envío de dinero del jugador 1 en el juego, percepción de la corrupción en el municipio de residencia en el último año, coincidencia o no con la afirmación: "los gobernantes son corruptos y trabajan por su propio beneficio", y coincidencia o no con la afirmación: "aquí se cumple la mayoría de 
las leyes que ordena el Estado”. Las cinco primeras son categóricas ordinales y las dos últimas dicotómicas naturales. Salvo el envío del jugador 1, los datos se tomaron de la encuesta diligenciada por cada participante al finalizar el experimento.

La distribución de los datos exige calcular dos tipos de coeficientes de correlación no paramétricos que relacionan variables categóricas ordinales entre sí, y estas con binarias naturales: los coeficientes $\otimes$ de Spearman, de Kendall y de Goodman y Kruskal para el primer caso $^{6}$, y el coeficiente biserial puntual para el segundo (Agresti, 2010) ${ }^{7}$, que determinan la dirección y la fuerza del vínculo entre pares de variables teóricamente relevantes y relacionadas. Los coeficientes van de -1 a 1; el signo indica la dirección y el valor absoluto es más alto a medida que la relación es más estrecha. A pesar de que los coeficientes no imponen ningún supuesto sobre la distribución de la población de la que provienen las variables, algunas transformaciones permiten compararlos con la distribución estándar y hacer pruebas de independencia entre las variables, en las que la hipótesis es que el coeficiente de correlación estimado es cero.

El cuadro 2 presenta los resultados de las correlaciones de los cinco pares. Para los coeficientes entre variables categóricas ordinales se calcularon las tres pruebas mencionadas a fin de evaluar la consistencia estadística de los resultados. El número de observaciones varía en cada caso pues se prescindió de las observaciones de quienes no respondieron y en la tercera columna solo se consideran los participantes que asumieron el rol de jugador 1 .

${ }^{6}$ Los coeficientes $\rho, \tau_{\mathrm{b}}$ y $\gamma$ se usan aquí para relacionar variables categóricas ordinales. Sean $\left(x_{i}, y_{i}\right),\left(x_{j}, y_{i}\right)$ los rangos de un par de variables $x y y$, donde $1 \leq i, j \leq n$, y $n$ el número de observaciones. El coeficiente $\rho$ será el mismo de

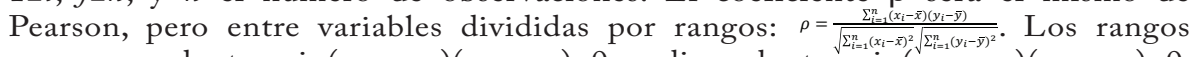
son concordantes si $\left(x_{i}-x_{j}\right)\left(y_{i}-y_{j}\right)>0$ y discordantes si $\left(x_{i}-x_{j}\right)\left(y_{i}-y_{j}\right)<0$. Sea $C$ el número de pares concordantes y $D$ el de discordantes. Si $N=n(n-$ 1)/2 es el número total de pares, $\tau_{\mathrm{b}}$ se puede expresar como $\tau_{b}=\frac{c-D}{\sqrt{N-U} \sqrt{N-V}}$, donde $U=\sum_{i=1}^{N_{1}} u_{i}\left(u_{i}-1\right) / 2, V=\sum_{j=1}^{N_{2}} u_{j}\left(u_{j}-1\right) / 2 . N_{1}$ es el número de combinaciones con iguales valores de $x, u_{i}$ el número de iguales valores de $x$ en la i-ésima combinación, $N_{2}$ el número de combinaciones con iguales valores de $y, u_{i}$ el número de iguales valores de $y$ en la j-ésima combinación. El coeficiente $\gamma$, que no corrige por pares con valores iguales, se define así: $\gamma=\frac{c-D}{c+D}$. Para probar la independencia, se usan aproximaciones normales con correcciones de continuidad. En todos los casos se consideran varianzas asintóticas.

7 El coeficiente biserial puntual de correlación entre una variable dicotómica $d_{i}$ y una categórica ordinal $x_{i}$ se define como: $r_{b p}=\frac{m_{1}-m_{0}}{s_{n}} \sqrt{\frac{n_{1} n_{0}}{n^{2}}}$, donde $n$ es el tamaño de la muestra total, $s_{n}$ la desviación estándar, dada por $s_{n}=\sqrt{\frac{1}{n} \sum_{i=1}^{n}\left(x_{i}-\bar{x}\right)^{2}}, n_{0}$ y $n_{1}$ el tamaño de las submuestras cuando $d_{i}=0$ y $d_{i}=1$, respectivamente, y $M_{0}$ y $M_{1}$ el promedio de $x_{i}$ cuando $d_{i}=0$ y $d_{i}=1$. 
Los resultados concuerdan con lo que se esperaba. En primer lugar, hay más (menos) inclinación a confiar en el sistema judicial y en la alcaldía del municipio de residencia cuanta más (menos) confianza se tiene en la propia comunidad, y viceversa. En segundo lugar, los participantes en el juego de la confianza confían más (menos) en el compañero de juego cuanto menor (mayor) es su percepción de corrupción en el municipio de residencia en el último año, y viceversa. En tercer lugar, se tiende a pensar que los gobernantes que trabajan en su propio beneficio son corruptos cuanto más se percibe que ha habido corrupción en el municipio de residencia en el último año, y a pensar que no lo son cuanto menor es esa percepción. Y en cuanto a la idea de que en el lugar donde se encuentran "se cumple la mayoría de las leyes que ordena el Estado", tienden a estar de acuerdo cuando perciben menor corrupción y a disentir cuando perciben mayor corrupción.

Cuadro 2

Correlaciones, percepción de confianza y corrupción

\begin{tabular}{|c|c|c|c|c|c|c|}
\hline \multicolumn{2}{|c|}{ Coeficiente de correlación } & 1 & 2 & 3 & 4 & 5 \\
\hline de Snearman & Correlación & $0,1647^{*}$ & $0,2717^{* * * *}$ & $-0,3698^{* * * *}$ & & \\
\hline p ue speantinan & Valor $\mathrm{p}$ & 0,0901 & 0,0033 & 0,0026 & & \\
\hline & Correlación & $0,1470^{*}$ & $0,2383^{* * * *}$ & $-0,3323^{* * * *}$ & & \\
\hline$\tau_{\mathrm{b}}$ de Kendall & Valor $\mathrm{p}$ & 0,0849 & 0,0033 & 0,0024 & & \\
\hline$\gamma$ de Goodman & y Correlación & $0,2202^{*}$ & $0,3447^{* * *}$ & $-0,4728^{* * * *}$ & & \\
\hline Kruskal & Valor $\mathrm{p}$ & 0,0958 & 0,0023 & 0,0013 & & \\
\hline Biserial puntual & Correlación & & & & $0,3974^{* * *}$ & $-0,1597^{*}$ \\
\hline Observaciones & Va & 107 & 115 & 64 & $\begin{array}{c}0,0001 \\
116\end{array}$ & $\begin{array}{l}0,0815 \\
120\end{array}$ \\
\hline
\end{tabular}

Notas: 1. Confianza en la comunidad vs. confianza en el sistema judicial; 2. Confianza en la comunidad vs. confianza en la alcaldía; 3 . Envío jugador 1 vs. percepción de la corrupción en el último año; 4. De acuerdo con la afirmación "Los gobernantes son corruptos y trabajan por su propio beneficio" vs. percepción de la corrupción en el último año; 5. De acuerdo con la afirmación "Aquí se cumple la mayoría de las leyes que ordena el Estado" vs. percepción de la corrupción en el último año.

Ho: coeficiente de correlación $=0$; ${ }^{*}$ valor $\mathrm{p}<0,10$; ** valor $\mathrm{p}<0,05$; *** valor $\mathrm{p}<0,01$.

Todos los resultados son estadísticamente significativos. Los de la segunda, tercera y cuarta columnas al 99\% de confianza, y los demás al 90\%. Además, en las tres primeras correlaciones, entre variables categóricas ordinales, los resultados son consistentes para todos los coeficientes y pruebas de independencia. En todo caso, cabe recordar que "[el] $\rho$ de Spearman tiende a ser mayor en valor absoluto al $\tau$ de Kendall. Pero como prueba de significancia no hay ninguna razón para preferir el uno sobre el otro pues ambos producirán resultados casi idénticos en la mayoría de los casos" (Conover, 1999).

En la región existe una tradición de contrabando, informalidad $y$ poca presencia estatal, que se refleja en bajos niveles de confianza en el Estado y la inclinación a engañar a los funcionarios. En el Bajo 
Cauca el Estado ha mostrado históricamente una baja capacidad para cumplir las funciones básicas de un Estado moderno: regulación económica, tributación, control de la ilegalidad y prevención de la rebelión (Giraldo, 2013). Esa percepción es tan arraigada que es usual que los mineros entrevistados digan: "legalizarse, formalizarse, solo tiene una ventaja: quitarnos de encima una vacuna, la de las autoridades locales" (minero informal, Bajo Cauca). Algunos habitantes, sobre todo los que pertenecen al sector minero, equiparan la acción del Estado con la de los grupos criminales. Un minero informal antioqueño señaló: "la minería es otra renta más para los poderosos (políticos, fuerza pública, guerrilleros, bacrim, paramilitares)”. E1 Estado central se percibe entonces como un interesado ocasional, que amenaza, presiona, consigue lo que quiere y abandona la región. Entre muchos mineros ronda la idea de que "el Estado actúa como otro criminal cuando cobra impuestos".

La inestabilidad y los vacíos normativos han sido constantes en el esfuerzo del Estado por regular el sector minero-energético (Giraldo y Muñoz, 2012). El artículo $10^{\circ}$ del Código de Minas fijó como objetivos fomentar la exploración y explotación técnica de los recursos mineros; satisfacer la demanda interna y externa; y aprovecharlos conforme a los principios y normas de explotación racional, en un marco de desarrollo sostenible y fortalecimiento económico y social del país. El gobierno modificó el Código en 2010 mediante la Ley 1382, que pretendía aclarar la distinción entre minería legal, informal e ilegal y dar al gobierno las herramientas para promover la formalización mientras combatía la ilegalidad. Pero la preocupación por las implicaciones ambientales de algunos de esos cambios llevó a que la Corte Constitucional la declarara inexequible con la Sentencia C-366 de 2011. Incapaz de ejercer control sin los recursos legales necesarios, el gobierno expidió varios decretos contra la minería ilegal, como el Decreto 2235 de octubre de 2012, que permitía a la policía destruir la maquinaria pesada que encontrara en una explotación sin título minero o licencia ambiental.

El gobierno ha entendido las dificultades para aplicar esas decisiones legales. Uno de los acuerdos para poner fin al paro minero de 2013 fue suspender el Decreto 2235. Y este no es el único caso de suspensión o aplazamiento de las normas por problemas de aplicación. El plan de desarrollo "Prosperidad para todos" introdujo la figura del RUCOM (Registro Único de Comercializadores de Minerales) para impedir la comercialización ilegal de oro. Pero su entrada en vigencia, el $1 .^{\circ}$ de enero de 2012, se prorrogó al $1 .^{\circ}$ de enero de 2014 , por la 
imposibilidad de aplicarla, como confirma la parte motiva del decreto que fijó el nuevo plazo.

Por falta de claridad para identificar y diferenciar a la minería legal, informal e ilegal el gobierno se ha centrado en la acción penal, lo que aumenta las oportunidades para intercambiar mercancías políticas y ha sido recibido con recelo y desconfianza por los mineros informales. Las dificultades legislativas para incluir a buena parte del sector minero se constatan en los municipios visitados: "El pequeño minero no existe en el código de minas" (minero informal, Segovia). Las perspectivas de formalización enfrentan grandes desafíos, pues como dice ese minero: "No podemos ser legales por no tener un título, si no podemos conseguir un título porque ahora todo está titulado". No es sorprendente que ese minero del nordeste antioqueño concluya que en su municipio "La gente no confía en el Estado".

La inestabilidad de las normas sobre la explotación de oro ha agravado la desconfianza en las organizaciones estatales. La caída del proyecto que reformaba el Código Minero, la mención de la "minería criminal" en el plan de desarrollo nacional y el decreto que autorizó la destrucción de maquinaria crearon enormes vacíos normativos. Y como afirma un congresista entrevistado, "los ilegales, corruptos y bandidos [son] los que se benefician de la inseguridad jurídica" (entrevista del 14 de agosto de 2013).

Gráfica 3

Confianza en organizaciones

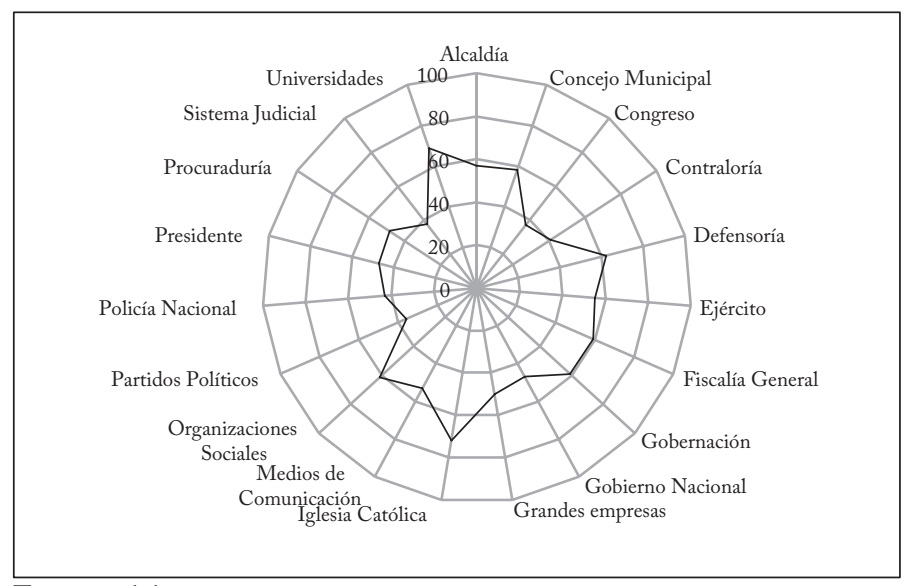

Fuente: elaboración propia.

Los resultados del trabajo de campo confirman la percepción de los entrevistados sobre la desconfianza en el gobierno nacional. Y dan 
otras pistas sobre la relación entre los participantes en los experimentos y otras organizaciones (gráfica 3).

La relación entre confianza general y confianza en la alcaldía muestra la importancia del gobierno local en la dinámica municipal (gráfica 4). El papel de los alcaldes como fuerza política e incluso económica se remonta a la reforma de 1986 que introdujo su elección popular. En los municipios los alcaldes toman algunas de las decisiones más importantes, tienen recursos económicos y políticos para asegurar su influencia durante su mandato e incluso después.

Gráfica 4

Confianza y confianza en alcaldía

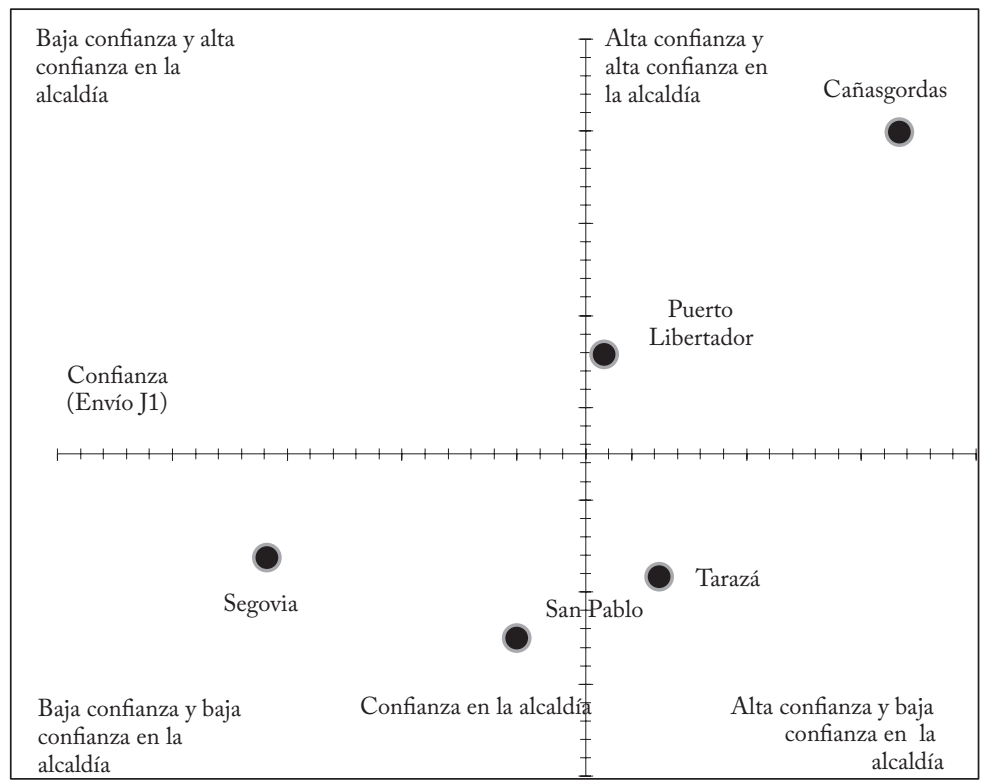

Los municipios mineros no son una excepción. En una de las entrevistas, un funcionario señaló que el alcalde tiene un papel predominante en todas las decisiones importantes. Y reconoció incluso que la ejecución de los recursos de inversión del municipio depende, en gran medida, de la voluntad política y la honestidad del alcalde del momento. Los datos recogidos también sugieren una relación entre la percepción de corrupción de los participantes en los experimentos y su confianza en la alcaldía (gráfica 5).

Las tres organizaciones que gozan de más confianza -según el porcentaje que dice confiar algo o mucho en cada una- en toda la muestra fueron la Iglesia Católica (72\%), las universidades (69\%) 
y las organizaciones sociales (61\%). La confianza en ellas resultó consistente en la mayoría de los casos, salvo la calificación de las organizaciones sociales en Segovia (41\%). Es llamativo el bajo puntaje de confianza en la policía (43\%) y el ejército (55\%), que se desempeñan notablemente mejor en sondeos similares. Pero las entrevistas dan luces a este respecto: la percepción de los pobladores de algunos municipios parece basarse en el desgaste provocado por el conflicto armado, en sus consecuencias locales y en el abandono del gobierno central, como indica una confianza en el gobierno nacional del $47 \%$. Las mayores muestras de desconfianza en toda la muestra corresponden al sistema judicial (38\%), al Congreso de la República (37\%) y a los partidos políticos (36\%).

\section{Gráfica 5}

Percepción de corrupción y confianza en la alcaldía

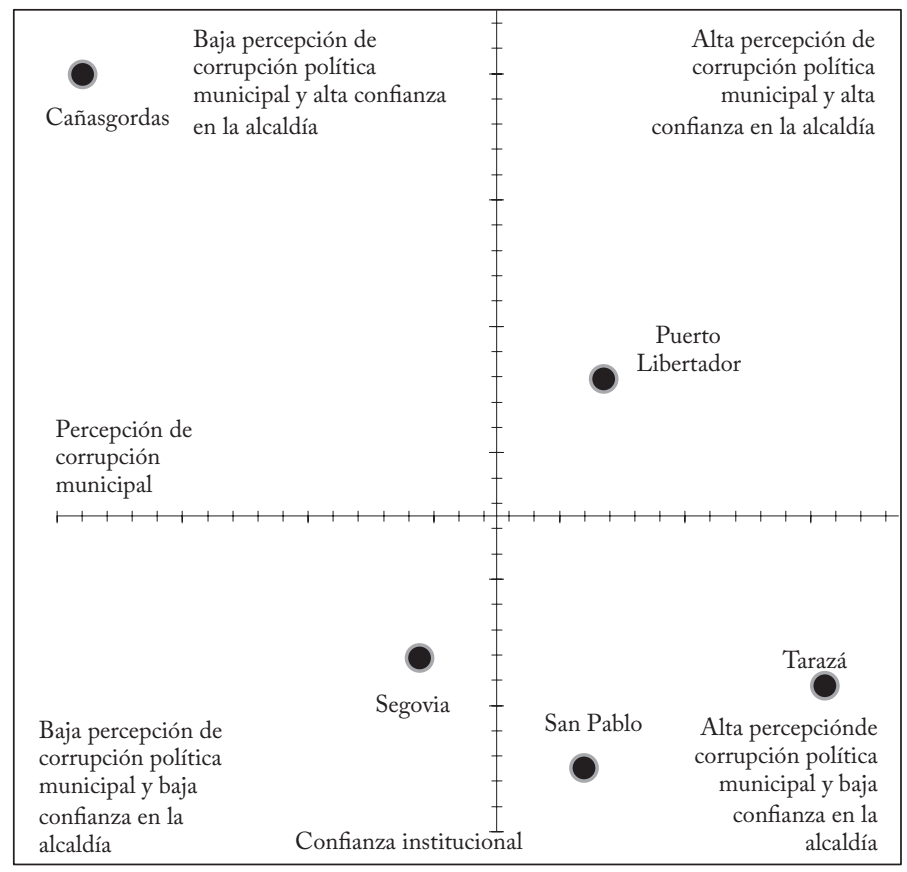

Los resultados de las preguntas sobre la confianza en algunos grupos (familia, vecinos, comunidad y recién conocidos) muestran que esta cambia a medida que el círculo se aleja (gráfica 6).

El tercer juego buscaba dar luces sobre la disposición a hacer trampa en circunstancias específicas. Cada participante recibía un vaso y un dado de seis caras que debía lanzar una vez para establecer el pago, 
proporcional al resultado del lanzamiento. Los resultados muestran dos actitudes (gráfica 7). Un buen número de los participantes hizo trampa cuando tuvo la oportunidad. Sin riesgo de ser capturados o castigados, sin ningún costo y con un beneficio, muchos reportaron un número mayor al que obtuvieron en el lanzamiento del dado. Otro grupo decidió reportar el resultado real a pesar de que así obtendría un pago menor. No es difícil incentivar acciones deshonestas en escenarios donde todos los incentivos externos están dados. Pero detectar honestidad en un juego de este tipo es todo un hallazgo. Cerca del $24 \%$ de los participantes reportó 1,2 o 3; pese a que era posible hacer trampa con ganancias e impunidad.

Gráfica 6

Confianza en grupos

(Porcentaje)

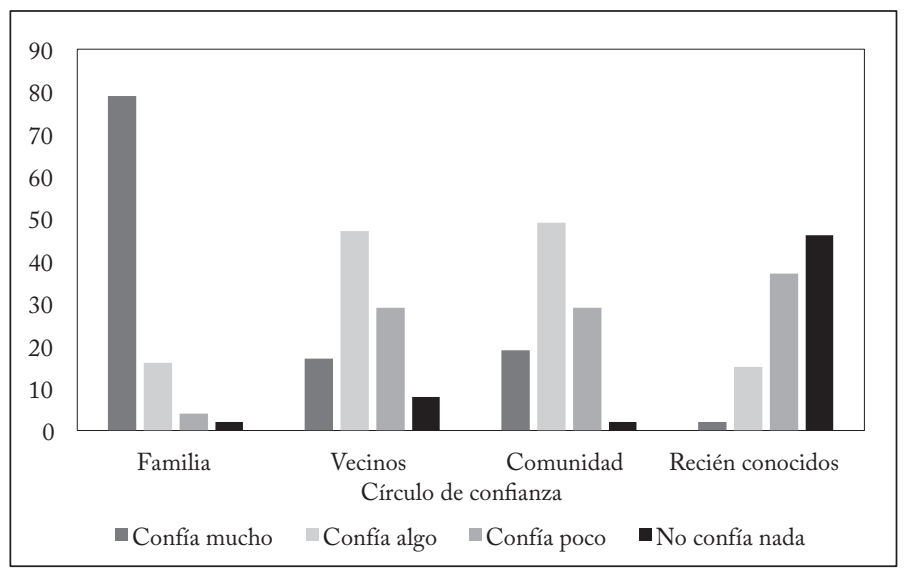

Gráfica 7

Disposición a la trampa

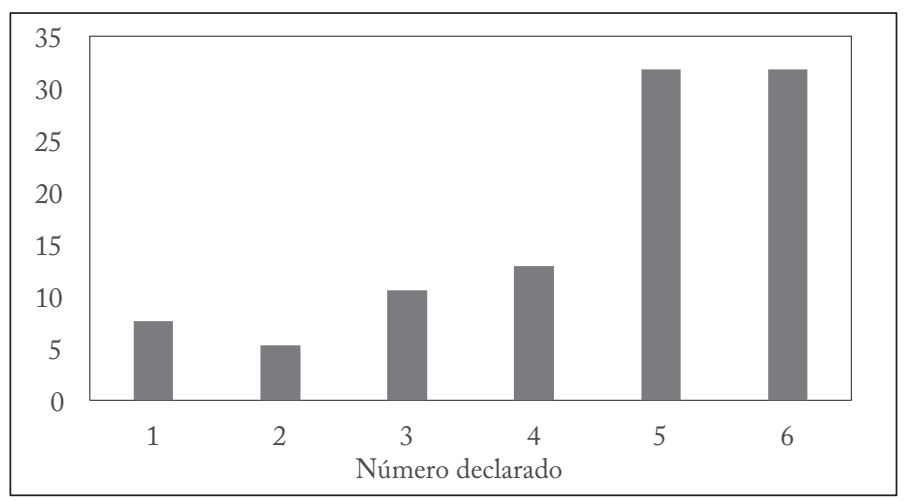

Revista de Economía Institucional, vol. i7, N. ${ }^{\circ} 33$, Segundo semestre/20i5, pr. 23 I-25 I 
También es interesante analizar a quienes reportaron 5. Aunque este grupo duplica la probabilidad teórica (el 16,7\%), los que reportaron 5 sin haberlo obtenido no reportaron 6 . Es decir, ante los mismos incentivos que los que reportaron 6 sin haberlo obtenido, parecen haberse abstenido, lo que sugiere una relación entre disposición a hacer trampa e interés por mantener un buen concepto personal como exigencia de la conciencia (Mazar et al., 2008). Hacer trampa no es un asunto simple y no depende únicamente de incentivos racionales o externos; hay otras razones para que las personas se comporten en forma honesta o, al menos, no tan deshonesta. La corrupción no solo se nutre de la desconfianza y la disposición a la trampa, requiere herramientas y espacios de interacción favorables. La oportunidad es un aspecto clave y las mercancías políticas son un instrumento que los agentes corruptos pueden emplear en sus intercambios. En el trabajo de campo se identificaron algunas de estas mercancías.

Por un lado, la extorsión de los grupos armados ilegales a las unidades de producción minera, sobre todo a las que pertenecen a pequeños mineros informales. Como dice un entrevistado: "cuando es con maquinaria pesada, todo el mundo quiere sacar su mejor partido, entonces, quien tenga más presencia ahí, es más fuerte, obviamente que sí hay cobros adicionales aparte de la declaratoria" (minero, San Pablo). La extorsión no se limita a la actividad minera; es una extensión de la "vacuna" que esos grupos cobran prácticamente a todas las actividades económicas. En San Pablo y Puerto Libertador, los entrevistados hablaron de extorsión a pequeños negocios comerciales, transportadores e incluso a contratistas de obras públicas. La extorsión es un gravamen ilegal a la actividad económica en el territorio que controlan los grupos armados ilegales.

Por otro lado, el acalde decide cómo invertir los recursos y aplicar la legislación policiva, lo que le permite usar las mercancías políticas. La política local se basa en redes clientelistas con profundas raíces en la tradición de los municipios. Algunos de los entrevistados se refieren a esta forma de conseguir apoyo político como la "única conocida". Uno de los principales medios que los políticos locales usan para mantener sus clientelas es el uso de los recursos públicos, sobre todo las regalías dispuestas por el Fondo Nacional de Regalías anterior ${ }^{8}$; aunque el alcalde -o el líder político local- mantiene su poder mediante inversiones y contratos municipales que alimentan sus radios de confianza. Como señala un investigador de Bogotá entrevistado,

\footnotetext{
${ }^{8}$ El nuevo Sistema General de Regalías impuso más controles a la distribución de recursos y centralizó la aprobación de proyectos.
} 
"repartir" entre familiares y amigos cercanos los recursos de ejecución de los contratos es casi una "necesidad" política para el líder local".

La debilidad administrativa y la tradición política de muchos municipios alientan las prácticas corruptas en la contratación pública. Pero las redes clientelistas locales forman parte de redes regionales e incluso nacionales. Algunos funcionarios municipales entrevistados resaltaron las relaciones entre el poder local (los alcaldes sobre todo), los congresistas y los ministros ${ }^{10}$. Incluso la aprobación de proyectos que benefician a los municipios depende de acuerdos políticos previos, como reconoce un alcalde entrevistado: "si ellos se los aprueban a uno [...] ahí tiene que hacer uno un compromiso político, le dicen a uno, me consigue voticos, adicional hay un porcentaje para mí, así se maneja este país".

La desigualdad legal también crea espacios para intercambiar mercancías políticas. El alcalde, pero sobre todo la Policía, tienen la facultad para cerrar minas ilegales, decomisar oro e incluso, conforme al Decreto 2235, destruir maquinaria pesada si faltan títulos mineros o licencias ambientales. La informalidad general en la producción minera de la región y las facultades que algunos funcionarios ejercen sin ningún control dan campo a cobros extralegales a la actividad minera informal.

\section{CONCLUSIONES}

Los cambios en las reglas modifican el comportamiento de los actores, no necesariamente en la dirección deseada. El nuevo Sistema General de Regalías pone freno a las prácticas corruptas más claras a nivel municipal, pero puede llevar a refinar la corrupción. Las nuevas normas pueden dificultarla, pero pueden obligar a hacer innovaciones en la evasión de los controles. Una de las prácticas más comunes se presenta en la contratación pública, y el Sistema General de Regalías contempla mecanismos para desalentar aquellas a que dio origen el modelo anterior. Pero estos mecanismos buscan blindar los recursos de las regalías, y las autoridades locales mantienen la autonomía sobre el presupuesto ordinario, en cuya ejecución hay una visible corrupción; de modo que aún faltan mecanismos para controlarla.

\footnotetext{
${ }^{9}$ Los contratistas "históricos" también tienen ventajas que pueden llevar a monopolizar los contratos: capital, recursos humanos, tradición y contactos políticos.

${ }_{10}$ Un alcalde comentó: "Uno tiene que estar en la gestión para mover los proyectos, y le voy a decir la gran verdad que sucede: uno de radicar proyectos, puede radicar proyectos, pero si no hay palanca política los proyectos se quedan ahí, uno hace el radicado y se lo da a un Senador amigo para que él le ayude, de lo contrario el proyecto se puede hundir".
} 
La inestabilidad normativa y los vacíos jurídicos alientan el surgimiento de nuevas mercancías políticas, y el cambio incesante de las normas de contratación abre espacio a la violación de los deberes de los funcionarios y al intercambio de mercancías políticas, pues crea oportunidades para una aplicación inconveniente de las normas. La concentración en algunas empresas contratistas puede eliminar la competencia que promueve la licitación pública, y los contratos directos también son caldo de cultivo para la corrupción, dadas las ventajas de los grandes contratistas.

La ineficacia, la ineficiencia y la corrupción del Estado son las principales fuentes de desconfianza y de su falta de legitimidad en los municipios mineros de la región. Su ausencia, una percepción general entre las autoridades locales y los habitantes, es un reto para un gobierno nacional que intenta extender su autoridad. Su esfuerzo se debería centrar en el entramado legal y en una política minera que tenga en cuenta las complejidades locales. Unas reglas de juego claras y estables y su justa aplicación generarían confianza y limitarían las mercancías políticas de que dispone el poder local tradicional. Y la adecuada acción del Estado podría modificar la percepción de que sus impuestos y controles solo se diferencian de los que cobran y ejercen los grupos criminales por el color del uniforme.

La corrupción se nutre del ocultamiento y el desconocimiento; sin acceso a información la veeduría enfrenta graves problemas. El desconocimiento del funcionamiento de las regalías y de los instrumentos de control de esos recursos provenientes desincentiva la participación ciudadana. De modo que las dificultades para obtener información y participar en actividades de control alimentan la apatía.

En ambientes de baja confianza en la esfera política y desigual distribución de la confianza interpersonal hay poca participación en el control formal de cuentas, y este poco influye en los actores corruptos. Como la denuncia es poco común cuando no se confía en el Estado, es necesario que a los mecanismos formales se sumen los mecanismos informales de control social. El trabajo de campo muestra que hay un ambiente propicio para esta opción. E1 86\% de los participantes en los experimentos pertenecía a una organización social, en especial a Juntas de Acción Comunal, de las que hacía parte el 40\%. Para combatir la corrupción es necesario alentar esta inclinación participativa, la reciprocidad y la disposición a castigar y perdonar.

La incertidumbre y la inestabilidad en la vida personal y en las relaciones comunitarias deterioran el capital social. En la minería del oro priman estas dos características: la movilidad de la actividad 
implica una continua migración, y la falta de técnica y de recursos para la explotación a pequeña escala generan un alto grado de incertidumbre. De aquí la necesidad de que la política minera contemple la construcción de capital social en las regiones mineras.

\section{REFERENCIAS BIBLIOGRÁFICAS}

1. Agresti, A. Analysis of ordinal categorical data, Hoboken, NJ, Wiley, 2010.

2. Banfield, E. The moral basis of a backward society, Glencoe, The Free Press, 1958.

3. de Speville, B. Superando la corrupción, Bogotá, Planeta, 2011.

4. Eslava, A. El juego de las políticas públicas: reglas y decisiones sociales, Medellín, Universidad EAFIT, 2011.

5. Eslava, A., ed. Oro como fortuna. Instituciones, capital social y gobernanza de la minería aurífera colombiana, Medellín, Universidad EAFIT, Colciencias, 2014.

6. Fukuyama, F. Social capital and civil society, IMF Institute, 2000.

7. Gambetta, D. "Mafia: The price of distrust", D. Gambetta, Making and breaking cooperative relations, Oxford, Basil Blackwell, 2000, pp. 158-175.

8. Giraldo, J. “E1 gobierno del oro en el Bajo Cauca. Una lectura weberiana sobre la explotación aurífera no legal”, J. Giraldo, ed., Economía criminal y poder politico, Medellín, Universidad EAFIT, Colciencias, 2013, pp. 33- 69.

9. Giraldo, J. y J. C. Muñoz. Informalidad e ilegalidad en la explotación del oro y la madera en Antioquia, Medellín, Universidad EAFIT, Proantioquia, 2012.

10. Kliksberg, B. “¿Por qué la cultura es clave para el desarrollo?”, B. Kliksberg y A. Sen, Primero la gente, Barcelona, Ediciones Deusto, 2007, pp. 263-286.

11. Mazar, N.; O. Amir y D. Ariely. "The dishonesty of honest people: A theory of self-concept maintenance". Journal of Marketing Research 45, 6, 2008, pp. 633-644.

12. Misas, G.; M. J. Oviedo y A. Franco. La lucha anticorrupción en Colombia: teorías, prácticas y estrategias, Bogotá, Contraloría General de la República, 2005.

13. Misse, M. "E1 delito como parte del mercado ilegal: violencia, mercancía política y narcotráfico en Río de Janeiro”, R. Stanley, Estado, violencia y ciudadanía en América Latina, Madrid, Entimema, 2009, pp. $109-127$.

14. Misse, M. "Estado y mercados ilegales en Latinoamérica: reflexiones a partir del concepto de mercancía política”, J. Giraldo, ed., Economía criminal y poder político, Medellín, Universidad EAFIT, 2013, pp. 10-32.

15. Morck, R., y B. Yeung. "Family control and the rent-seeking society", Entrepreneurship Theory and Practice 28, 4, 2004, pp. 391-409.

16. Orrego L., C. Corrupción y modernización del Estado, Washington D.C., BIRD, 2000. 
17. Ostrom, E. Understanding institutional diversity, Princeton, Princeton University Press, 2009.

18. Ostrom, E. y M. Polski, "An institutional framework for policy analysis and design, 1999, [https://mason.gmu.edu/ mpolski/documents/ PolskiOstromIAD.pdf].

19. Rose-A. S. "Economía política de la corrupción”, M. Merino, ed., Ética pública, México, D. F., Siglo XXI, 2010, pp. 132-158.

20. SIMCO. "Producción de oro", consulta de febrero de 2013, [www. simco.gov.co].

21. Tilly, C. Confianza y gobierno, Buenos Aires, Amorrortu, 2005.

22. Uslaner, E. M. Trust and corruption, J. E. Lambsdorf, ed., Corruption and the new institutional economics, Londres, Routledge, 2004.

23. Uslaner, E. M. "Corruption, inequality and trust", G. Svendsen y S. G. Lind, The handbook of social capital, Londres, Edward Elgar, 2009. 